\title{
Evidence for inbreeding depression in the tree Robinia pseudoacacia L. (Fabaceae)
}

\author{
C.Q. Yuan ${ }^{1 *}$, Y.F. Li ${ }^{1 *}$, L. Wang ${ }^{2}$, K.Q. Zhao ${ }^{1}$, R.Y. Hu ${ }^{1}$, P. Sun ${ }^{1}$, Y.H. Sun ${ }^{1}$, \\ Y. Li ${ }^{1}$, W.X. Gu ${ }^{3}$ and Z.Y. Zhou ${ }^{3}$ \\ ${ }^{1}$ National Engineering Laboratory for Tree Breeding, \\ Key Laboratory of Genetics and Breeding in Forest Trees and Ornamental Plants, \\ College of Biological Sciences and Biotechnology, Beijing Forestry University, \\ Ministry of Education, Beijing, China \\ ${ }^{2}$ College of Forestry, Beijing Forestry University, Beijing, China \\ ${ }^{3}$ College of Biological Sciences and Biotechnology, \\ Beijing Forestry University, Beijing, China \\ *These authors contributed equally to this study. \\ Corresponding author: $\mathrm{Y}$. Li \\ E-mail: yunli63@gmail.com
}

Genet. Mol. Res. 12 (4): 6249-6256 (2013)

Received January 2, 2013

Accepted May 24, 2013

Published December 4, 2013

DOI http://dx.doi.org/10.4238/2013.December.4.12

\begin{abstract}
The magnitude of inbreeding depression within populations is important for the evolution and maintenance of mixed mating systems. However, data are sparse on the magnitude of inbreeding depression in Robinia pseudoacacia. In this study, we compared differences in the mature seed set per fruit, seed mass, germination success, and seedling growth between self- and crosspollination treatments and estimated the inbreeding depression at 3 stages: seed maturation, seedling emergence, and seedling growth at 10 and 20 weeks. We found that progenies resulting from cross-pollination treatments showed significantly higher fitness than progenies resulting from self-pollination, causing high levels of inbreeding depression. Inbreeding depression was not uniformly manifested, however, over the 3 stages. Inbreeding depression was the greatest between fertilization
\end{abstract}


and seed maturation stage $(\delta=0.5419)$, and the seedling emergence $(0.3654)$ stage was second. No significant differences in seedling growth were observed between selfed and crossed progenies. The cumulative inbreeding depression $(\delta)$ across all 3 stages averaged 0.7452 . Inbreeding depression may promote outcrossing in $R$. pseudoacacia by acting as a post-pollination barrier to selfing. The large difference in the seed set between self- and cross-pollination that we detected indicated that inbreeding depression would probably be a reasonable explanation for the high abortion and low seed set in R. pseudoacacia.

Key words: Robinia pseudoacacia L.; Fitness; Inbreeding depression; Mating system

\section{INTRODUCTION}

Robinia pseudoacacia are a deciduous tree that belongs to the Fabaceae (legume) family. The flowers are pollinated by insects, especially bees. $R$. pseudoacacia are well adapted for growth in a wide variety of soils and environmental conditions and are used for lumber, fuel, feedstock, wood fiber, forage, and applications such as beekeeping, land reclamation, and energy plantations (Harlow et al., 1979; Barrett et al., 1990; Bongarten et al., 1992). Because of its nitrogen fixing ability, superior growth rates, energy yield, and other attractive features, such as salt and alkali resistance, drought and cold tolerance, and extensive adaptability, R. pseudoacacia has been introduced in Europe, Asia, Australia, South America, and Africa, where it has undergone a rapid expansion and become naturalized in many countries (Keresztesi, 1983). It was first introduced to China in 1877-1878 and is now a popular and important ecological species that is extensively cultivated in many parts of China (Li, 1983).

Fruit and seed set in R. pseudoacacia were low: most ovules fail to develop within the mutliseeded fruits of $R$. pseudoacacia (Susko, 2006). Earlier studies (Surles et al., 1990) pointed out that the physical separation of stigmatal and antheral surfaces as well as the protogynous flowering habit of $R$. pseudoacacia encourage outcrossing, but variation in flower maturity within trees provides an opportunity for geitonogamous selfing. Previous allozyme analysis of $23 R$. pseudoacacia seed sources from the eastern United States showed that the probability of outcrossing was significantly lower than 1.0, with an average of 0.83 , indicating that it is a highly outcrossing species (Surles et al., 1990). The study also revealed that trees produced at least some seeds by means of self-fertilization. However, the low fruit and seed set along with the high seed abortion in $R$. pseudoacacia were unknown.

Generally speaking, two possible mechanisms - late-acting self-incompatibility and inbreeding depression (Stephenson, 1981; Seavey and Bawa, 1986) - are believed to give rise to selective differences in survival in the earliest life-cycle stages. In the case of late-acting self-incompatibility, selection against self-fertilized ovules occurs prior to seed maturation (Hufford and Hamrick, 2003). Inbreeding depression is the reduced fitness of self-fertilized progeny due to either the loss of overdominant effects of heterozygotes or increased expression of recessive deleterious alleles (Wright, 1921; Charlesworth 
and Charlesworth, 1987; Hufford and Hamrick, 2003). Fitness differences due to inbreeding depression may affect progeny survivorship at any stage of the life cycle (Hufford and Hamrick, 2003). Models and empirical observations indicate that high levels of inbreeding depression are experienced early in the life cycle in predominantly outcrossing species (Lande and Schemske, 1985; Schemske and Lande, 1985), but information is sparse regarding the selection mechanism and role of inbreeding depression in the reproductive success of $R$. pseudoacacia.

In this study, we investigated the evidence for post-zygotic inbreeding breeding by testing the performance of selfed and outcrossed progeny across 3 early life stages to determine the magnitude and timing of inbreeding depression.

\section{MATERIAL AND METHODS}

\section{Study species and site}

R. pseudoacacia is a nitrogen-fixing leguminous forest tree species that is extensively cultivated in many parts of the world. It is monoecious, insect-pollinated, and protogynous, but their asynchronous flowering within a tree causes high self-fertilization as a result of frequent geitonogamy (Surles et al., 1990). Manual pollination experiments were conducted in Mijiabu tree farm $\left(40^{\circ} 30^{\prime} 302^{\prime \prime} \mathrm{N}, 116^{\circ} 00^{\prime} 015^{\prime \prime E}\right)$, Yanqing, Beijing, China, where $R$. pseudoacacia has continuously maintained a large population. The germination test and the nursery experiment were conducted at the Beijing Forestry University Greenhouse in Beijing.

\section{Controlled pollination experiments}

To obtain the selfed and outcrossed seeds, we conducted manual self- and cross-pollinations on 6 randomly chosen trees from 2009 to 2012. Two hundred inflorescences per maternal tree were selected; 100 were subjected to self-pollination treatments and another 100 were used for cross-pollination. For self-pollination, each maternal tree was pollinated by pollen from the same maternal tree. For cross-pollination, each maternal tree was pollinated by a pollen donor that was collected from the Beijing Forestry University campus. Flowers were emasculated at flower budding stage with calyx: corolla $=1: 1$, one-third length of corolla of flower was removed carefully with forceps and then all 10 stamens were cut at one-third length. Special care was taken not to injure the female part of the flower. Pollen, collected from flowers at corolla elongating stage (calyx:corolla $=1: 2$ ) by tapping the anthers gently onto a Petri dish, was applied to the target stigma with cotton swabs at 8:00 am, 1 day before anthesis and the very day of anthesis, when the stigma was at optimal receptivity. Visitors were excluded from the flowers by covering the flowers with nets. Nets were removed one week after pollination to return flowers to natural illumination and ambient temperature. Fruits were collected in October.

\section{Germination test and nursery experiment}

A germination experiment was conducted using selfed and outcrossed seeds that 
were obtained from manual pollinations. The number of selfed and outcrossed seeds obtained per maternal tree ranged from 84 to 212 and 41 to 238, respectively. The seeds were placed on moist filter paper on Petri dishes and soaked with $70^{\circ} \mathrm{C}$ water for $24 \mathrm{~h}$. The seeds were then placed on new moist filter paper on Petri dishes for another $48 \mathrm{~h}$ and then were planted in a seedling bag $($ diameter $=12.5 \mathrm{~cm}$, height $=12.5 \mathrm{~cm})$ containing potting soil $(1: 1: 1: 0.5$ roseite:turfy soil:sand:perlite). Pots were placed in racks and were $2 \mathrm{~cm}$ apart. Plants were grown in a phytotron under the following conditions: 12 -h light $/$ dark; $25^{\circ} \mathrm{C}$ light $/ 18^{\circ} \mathrm{C}$ dark; 6.7 flux lumen output; and $70 \%$ humidity. We measured seedling emergence after 4 weeks and seedling height after 10 and 20 weeks. Seedling diameter was measured after 20 weeks. Seedling emergence was calculated according to the following equation: Seedling emergence $=$ (Number of seedlings $/$ Initial number of seeds $)$.

\section{Statistical analysis}

For each fruit, we calculated the seed abortion rate per fruit (number of aborted seeds per fruit / total number of seeds per fruit) and the proportion of mature seeds per fruit (number of mature seeds per fruit / total number of seeds per fruit) to test for differences among pollination treatments. Ovules that had expanded in size and had begun some development of the embryo and seed coat, but were much smaller than a fully mature seed, were treated as aborted seeds. Mature seeds were brown-black and plump, with a completely formed seed coat (according to the standards of Susko, 2006). The mature seed mass was weighed individually.

We analyzed the effect of self- and cross-pollination treatment on 6 properties (mature seed set per fruit, seed mass, seed abortion rate per fruit, seedling emergence, seedling diameter, and seedling height) using a generalized linear model with univariate analysis of variance. Arcsine transformation was adopted for the analysis of mature seed set per fruit and seedling emergence. Analyses were performed using SPSS (version 16, Chicago, IL, USA).

The magnitude of inbreeding depression $(\delta)$ at stages of seed maturation, seedling emergence, and seedling size was calculated by $\delta=1$ - (mean fitness of selfed progeny / mean fitness of crossed progeny), cumulative mean fitness of progeny $=\mathrm{f} 1 \mathrm{x} f 2 \times \mathrm{f} 3 \mathrm{x} \mathrm{f} 4 \mathrm{xf} 5 \mathrm{x} f 6$, where $f 1$ to $f 6$ indicates the fitness of the 6 traits, and cumulative inbreeding depression $(\delta)=$ 1- (cumulative mean fitness of selfed progeny / cumulative mean fitness of crossed progeny) (Johnston and Schoen, 1994).

\section{RESULTS}

\section{Pollination treatment effects}

There were significant differences in the mature seed set and seed mass with self- and cross-pollination. Crossed flowers produced approximately 2.2 times as many mature seeds as selfed flowers. However, the seed abortion rate per fruit from cross-pollination was significantly lower than that from self-pollination (Table 1). Meanwhile, the average individual seed mass was higher in the crossed treatment than in the selfed treatment. The effect of the interaction between the tree and the treatment was significant for the mature seed set per fruit and the seed abortion rate per fruit, indicating variations in fitness and different levels of inbreeding depression between the maternal trees (Table 1). 


\begin{tabular}{|c|c|c|c|c|c|}
\hline \multirow[t]{2}{*}{ Stage } & \multicolumn{2}{|c|}{ Means \pm SD } & \multirow[t]{2}{*}{$\delta$} & \multicolumn{2}{|c|}{ ANOVA $F$} \\
\hline & Selfed & Outcrossed & & Treatment & Interaction \\
\hline Mature seed set per fruit & $0.1607 \pm 0.0633$ & $0.3508 \pm 0.3364$ & 0.5419 & $33.764 * *$ & $4.317 * *$ \\
\hline Seed abortion rate per fruit & $0.3205 \pm 0.2819$ & $0.2514 \pm 0.2616$ & - & $8.075^{*}$ & $2.452 *$ \\
\hline Seed mass $(\mathrm{g})$ & $0.0148 \pm 0.0070$ & $0.0157 \pm 0.0163$ & 0.0573 & $3.893^{*}$ & $1.497 \mathrm{~ns}$ \\
\hline Seedling emergence & $0.1973 \pm 0.0976$ & $0.3109 \pm 0.1558$ & 0.3654 & $10.999 *$ & - \\
\hline Seedling height at 10 weeks $(\mathrm{cm})$ & $9.0820 \pm 2.8794$ & $9.2979 \pm 3.9804$ & 0.0232 & $1.712 \mathrm{~ns}$ & $3.740 *$ \\
\hline Seedling height at 20 weeks $(\mathrm{cm})$ & $10.45 \pm 3.01$ & $11.45 \pm 4.50$ & 0.0873 & $0.965 \mathrm{~ns}$ & $3.442 *$ \\
\hline Seedling diameter at 20 weeks (mm) & $3.1077 \pm 0.7019$ & $2.9795 \pm 0.7805$ & -0.0430 & $1.054 \mathrm{~ns}$ & $0.441 \mathrm{~ns}$ \\
\hline Cumulative means & 0.1384 & 0.5431 & 0.7452 & - & - \\
\hline
\end{tabular}

ns $=$ not significant at $\mathrm{P}<0.05 . * \mathrm{P}<0.05 ; * * \mathrm{P}<0.01$

Of the total 809 seeds, 232 germinated successfully and 211 survived to 20 weeks. The seedling emergence from cross-pollination was higher than that from self-pollination (Table 1). The difference in this value between treatments was significant (Table 1).

The 10- and 20-week seedling heights from cross-pollination were higher than those from self-pollination; however, the difference in seedling height between treatments was not significant (Table 1). In contrast, the self-pollination seedlings showed a slightly larger seedling diameter at 20 weeks than the cross-pollination seedlings. The effect of the interaction between the tree and the treatment was significant for seedling height (Table 1). In contrast, neither the effect of treatment nor that of the interaction between the tree and the treatment was significant for the seedling diameter at 20 weeks (Table 1).

\section{Inbreeding depression at early stages}

Across all 3 life stages, selfed progeny exhibited reduced fitness compared with outcrossed progeny (Table 1). The inbreeding depression was not uniformly manifested, however, over the 3 stages. The inbreeding depression was the greatest between fertilization and seed maturation $(\delta=0.5419)$, with outcrossed flowers producing approximately 2.2 times as many mature seeds as selfed flowers; seedling emergence $(0.3654)$ had the second highest inbreeding depression (Table 1). Inbreeding depression $(\delta)$ values for seedling height at 10 and 20 weeks were 0.0232 and 0.0873 , respectively. In contrast, the seedling diameter at 20 weeks was slightly higher in selfed progeny than in crossed progeny. The cumulative inbreeding depression $(\delta)$ across all 3 stages averaged 0.7452 (Table 1).

\section{DISCUSSION}

Manual pollination experiments demonstrated that the mature seed set per fruit from self-pollination was significantly lower than that from cross-pollination and that the average individual seed mass was higher in cross-pollination treatment than in selfed treatment. However, we found that the frequency of aborted seeds from self-pollination was significantly higher than that from cross-pollination. In contrast, there were no significant differences between self- and cross-pollination for fruit set, fruit length, fruit diameter, and fruit weight (Yuan, 2013). These results indicate that inbreeding depression is a more likely explanation for the lowered seed production by selfed flowers than partial prezygotic self-incompatibility (self-incompatibility occurring before fertilization): if self-incompatibility was acting before 
fertilization, an increased proportion of fruit abortion would have occurred in the selfed fruits. Furthermore, we found a significant effect of the interaction between the tree and the treatment on the proportion of aborted seeds. Because most previous studies detected a high variance in the number of lethal equivalents per plant (Lynch and Walsh, 1998), this result can likewise be explained by inbreeding depression due to deleterious mutations rather than prezygotic self-incompatibility.

The magnitude and time of inbreeding depression is a crucial parameter in the evolution of the mating system and pollination strategies (Charlesworth and Charlesworth, 1987). Inbreeding depression plays a central role in mating system evolution. The consequences of it have also become an important issue in conservation biology, and it is currently considered to be one of the most important threats to the persistence of rare taxa (Hedrick and Kalinowski, 2000; Bellusci et al., 2009). However, inbreeding depression has not been studied in $R$. pseudoacacia. A previous study of $R$. pseudoacacia (Surles et al., 1990) suggested that protogyny and mass flowering, as well as the physical separation of stigmatal and antheral surfaces, encourage outcrossing; with the addition of insect-pollination, $R$. pseudoacacia has a mixed mating system (Surles et al., 1990). However, variation in flower maturity within trees of $R$. pseudoacacia provides an opportunity for geitonogamous selfing. Our other results (Yuan, 2013) indicated that the species was self-compatible and that autogamy can occur in R. pseudoacacia. Previous allozyme analysis of 23 R. pseudoacacia seed sources from the eastern United States showed that the probability of outcrossing was significantly lower than 1.0, with an average of 0.83 , indicating that it is predominantly an outcrossing species. Additionally, the study also revealed that trees produced at least some seeds by means of self-fertilization (Surles et al., 1990). In these cases, inbreeding depression seems to play an important role in the maintenance of reproductive traits that promote outcrossing.

Many studies have demonstrated that levels of inbreeding depression vary across life history stages; some plants exhibit the highest inbreeding depression values during seed production (Husband and Schemske, 1995; Kittelson and Maron, 2000; Ishida et al., 2003), while the inbreeding depression is more strongly expressed in other plants at later life history stages (Husband and Schemske, 1996). Plants that are primarily selfers express the majority of their inbreeding depression late in the life cycle, during growth and reproduction, whereas outcrossers express much of their inbreeding depression either early, at seed production, or late (Husband and Schemske, 1996). In our study, we demonstrated that $R$. pseudoacacia expresses inbreeding depression both at the seed maturation and at the seedling emergence stages. Our results confirmed the suggestion of Surles et al. (1990) that the germination rates from 23 R. pseudoacacia seed sources were positively correlated with outcrossing rates. In the 3 life stages that we examined, the highest inbreeding depression was observed between fertilization and seed maturation $(\delta=0.54)$. No differences in seedling growth were observed between self- and cross-pollination treatments. In contrast, the selfed progeny even showed a slightly greater seedling diameter at 20 weeks. These observations indicated that the significant selection event in $R$. pseudoacacia occurred at the time of seed maturation and germination success; after establishment, the progenies from different pollination treatments have same opportunity to compete and grow. The average cumulative inbreeding depression $(\delta)$ in $R$. pseudoacacia was 0.7452 , which was higher than the average inbreeding depression $(\delta=0.53)$ in predominantly outcrossing species (Husband and Schemske, 1996). Because we did not compare seedling survival in natural conditions or follow traits beyond the juvenile stage, our observed value may be an underestimate.

Compared with progeny that resulted from cross-pollination, the offspring that arose 
from self-pollination treatments showed substantial signs of inbreeding depression both at the seed maturation and at the seedling emergence stages in $R$. pseudoacacia. Given the less mature seed set and increased seed abortion rate in self-pollination than in cross-pollination, we argue that inbreeding depression is a reasonable explanation for the high abortion and low seed set in $R$. pseudoacacia. These are the first published data on the magnitude of the inbreeding depression following manual pollination in $R$. pseudoacacia.

However, the inbreeding depression that we detected only stems from uniparental inbreeding. We did not investigate biparental inbreeding in $R$. pseudoacacia. To more fully understand the causes of seed abortion and inbreeding depression in this species, however, further studies of pollen tube behavior, embryogenesis, fitness, and inbreeding depression from biparental inbreeding and in late life stages are needed. These questions are currently under investigation.

\section{ACKNOWLEDGMENTS}

Research supported by the Scientific Research of the Forest Public Welfare Industry (\#201004008) and the National Science Foundation of China (\#31170629). We also thank the 2 anonymous reviewers for their critical reading and valuable comments on the manuscript.

\section{REFERENCES}

Barrett RP, Mebrahtu T and Hanover JW (1990). Black Locust: A Multi-Purpose Tree Species for Temperate Climates. Timber Press, Portland.

Bellusci F, Pellegrino G and Musacchio A (2009). Different levels of inbreeding depression between outcrossing and selfing Serapias species. Biol. Plantarum 53: 175-178.

Bongarten BC, Huber DA and Apsley DK (1992). Environmental and genetic influences on short-rotation biomass production of black locust (Robinia pseudoacacia L.) in the Georgia Piedmont. For. Ecol. Manage 55: 315-331.

Charlesworth D and Charlesworth B (1987). Inbreeding depression and its evolutionary consequences. Ann. Rev. Ecol. Syst. 18: 237-268.

Harlow WM, White FM, Harrar ES and Hardin JW (1979). Text Book of Dendrology. McGraw Hill, New York.

Hedrick P and Kalinowski S (2000). Inbreeding depression in conservation biology. Annu. Rev. Ecol. Evol. 31: 139-162.

Hufford KM and Hamrick JL (2003). Viability selection at three early life stages of the tropical tree, Platypodium elegans (Fabaceae, Papilionoideae). Evolution 57: 518-526.

Husband BC and Schemske DW (1995). Magnitude and timing of inbreeding depression in a diploid population of Epilobium angustifolium (Onagraceae). Heredity 75: 206-215.

Husband BC and Schemske DW (1996). Evolution of the magnitude and timing of inbreeding depression in plants. Evolution 50: 54-70.

Ishida K, Yoshimaru H and Ito H (2003). Effects of geitonogamy on the seed set of Magnolia obovata Thumb. (Magnoliaceae). Int. J. Plant Sci. 164: 729-735.

Johnston MO and Schoen DJ (1994). On the measurement of inbreeding depression. Evolution 48: 1735-1741.

Keresztesi B (1983). Breeding and cultivation of black locust, Robinia pseudoacacia, in Hungary. Forest Ecol. Manag. 6: 217-244.

Kittelson PM and Maron JL (2000). Outcrossing rate and inbreeding depression in the perennial yellow bush lupine, Lupinus arboreus (Fabaceae). Am. J. Bot. 87: 652-660.

Lande R and Schemske DW (1985). The evolution of self-fertilization and inbreeding depression in plants. I. Genetic models. Evolution 39: 24-40.

Li JH (1983). The introduction and development of Robinia pseudoacacia in Shandong. J. Shandong Forest. Sci. Technol. 4: 73-75.

Lynch M and Walsh B (1998). Genetics and Analysis of Quantitative Traits. Sinauer Associates Incorporated, Sunderland. Schemske DW and Lande R (1985). The evolution of self-fertilization and inbreeding depression in plants. II. Empirical 
observations. Evolution 39: 41-52

Seavey SR and Bawa KS (1986). Late-acting self-incompatibility in angiosperms. Bot. Rev. 52: 195-219.

Stephenson AG (1981). Flower and fruit abortion: proximate causes and ultimate functions. Annu. Rev. Ecol. Syst. 12: 253-279.

Surles S, Hamrick JL and Bongarten BC (1990). Mating systems in open-pollinated families of black locust (Robinia pseudoacacia L.). Silvae Genet. 39: 35-40.

Susko DJ (2006). Effect of ovule position on patterns of seed maturation and abortion in Robinia pseudoacacia (Fabaceae). Can. J. Bot. 84: 1259-1265.

Wright S (1921). Systems of mating. II. The effects of inbreeding on the genetic composition of a population. Genetics 6 : 124-143. 124-143.

Yuan CQ (2013). The Sexual Reproduction and Mating System of Robinia pseudoacacia L. (Fabaceae). Doctoral thesis, College of Biological Sciences and Biotechnology, Beijing Forestry University, Beijing. 